\title{
Digital feminist pedagogy and post-truth misogyny
}

\section{Jessica Ringrose}

\begin{abstract}
In this point of departure, I discuss using an intersectional feminist lens to explore Twitter traffic around Donald Trump's 2016 US election win in an MA module Sociology of Education. Next I reflect upon my experience of having the feminist content of my public Twitter account trolled during the election period. I argue Twitter provides a new mediated space for teaching and learning but feminist academics also face risks in the form of misogyny both online and off.
\end{abstract}

\section{KEYWORDS}

Trump; racism; sexism; intersectional feminism; digital public pedagogy; Twitter; trolling

Introduction: digital feminist public pedagogy

We are seeing increasing calls for academics to digitise themselves to reach a wider market of visibility in the current neoliberal academic marketplace (Lupton, Mewburn, and Thomson 2018). Twitter and other social media platforms have come to represent a new metric of self-worth. How many followers will tweet academic news in the form of opinions, but also links to blog, talks and published articles, is now part of determining the impact of academic work in and beyond the academy (Carrigan 2016). Academics are measured not only on their $\mathrm{H}$-indexes and google scholar citation metrics but upon numeric followings on sites like academia.edu; research gate; and wider public forums like Twitter (Duffy and Pooley 2017). As I have researched elsewhere, this digital domain changes the nature of feminist pedagogy; digital public pedagogy (Rich and Miah 2014) is both a promising terrain but also one marked by complexity presenting opportunity but also significant risk for feminists (see Mendes, Ringrose, and Keller 2018).

In this point of departure piece, I consider Twitter's usefulness as a teaching tool in higher education contexts taking a lecture delivered surrounding Trump's election as an example. I explore the interweaving of feminist pedagogy in our classrooms with 'public pedagogy' online (Trifonas 2012), which digitises our teaching in new ways.

I also discuss the fallout from my digital political participation on Twitter, detailing my experiences of being trolled and having my intersectional feminist analysis of sexual and racial violence lambasted as false, which relates directly to an era of post-truth politics, the topic of this special issue of Teaching in Higher Education.

\section{An intersectional feminist analysis of Trump's election win}

On November 10, 2016, myself and Victoria Showunmi one of the few Black women lecturers at the UCL Institute of Education delivered a joint lecture on MA Sociology of Education. We drew on Black Feminist and intersectional sociological scholarship (Crenshaw 1991) to explore themes of racism, misogyny and deep class cleavages that became the focal points of debate surrounding Trumps dramatic election 'win'. We opened the lecture by using Twitter to look at some of the hateful language championed by Trump, which we called 'Trump Pedagogy', to think about the educational dynamics of how trump was popularising, spreading and normalising speech that is supposed to be hard hitting, honest and reflective of the 'common interest', but is actually hate-speech and a rejection of global equity and human rights (Ringrose and Showunmi 2016). Trump has called women 'nasty', 'bitches' and boasted about 'grabbing them by the pussy'. He has said African Americans were 'lazy fools only good at eating, lovemaking and thuggery' and has called Mexican's 'rapists', Chinese 'cheats' and all Muslims 'potential threats', with the list of hate-based terminology escalating through his time in power. Drawing on Butler (1990) we argued this is a pedagogical dynamic that legitimates hate through performative repetition of rhetoric and certain key phrase. This happens through what Brian Massumi (2015) calls mass media affective modulation - targeted repetition over time solidifies into the 'new normal'. Strom and Martin $(2017,5)$ argue the common-sense aspects of Trump rhetoric operates to normalise ultra-conservative politics at the same time as promoting it as common sense, which shuts down complexity and critical thinking: In the wake of Trump's election, we argue that the U.S., and likely the Western world, is tran-sitioning from neoliberalism into a new political period that combines aspects 
of ultra-con-servatism, White ethno-nationalism, corporate statehood, and authoritarianism. As we move into this new political era, however, one point has become clear: good and common sense (Deleuze 2005) ways of understanding the world and the current political movements are unable to account for the complexity and contradictions inherent in the confluence of today's socio-political phenomena.

The lecture was a space to try to unpack some of the complexities surrounding the news coverage and 'sense-making' of Trump's win. The first analyses on social media pointed to a poor underclass or 'rust belt' of disenfranchised voters that had voted with their ignor-ance for Trump, similar to how working class Britain had made a 'protest vote' with Brexit. This was soon disputed, however, with the evidence that middle class, educated white Americans (men and women) had voted to secure their privilege, which commentators were calling a 'whitelash' (white backlash) (Figure 1).

The images of crying white women who supported Hilary Clinton sat in contradiction, however, with the exit polls where many white women, especially from the Christian Right were undisputed Trump supporters. This became a jumping off point for exploring what might lie behind the affective investments of a large demographic of US white women who will vote against a woman candidate (Hilary Clinton) in favour of what Canadian activist and anti-sexual harassment commentator Julia S. Lalonde below calls a 'racist rapist'.

By using a feminist intersectional lens to underscore the intersections of racism, sexism and classism we can understand how some women will support a sexist (and sexually violent) white man, before their own 'sex' which complicates the very idea of women's natural commonality and shared sameness (Collins 1990). In contrast, the data circulated on Twitter (Figure 2) indicated Black women in America were the heaviest supporters of Hilary Clinton. Identity and positionality is always organised through class, race, gender

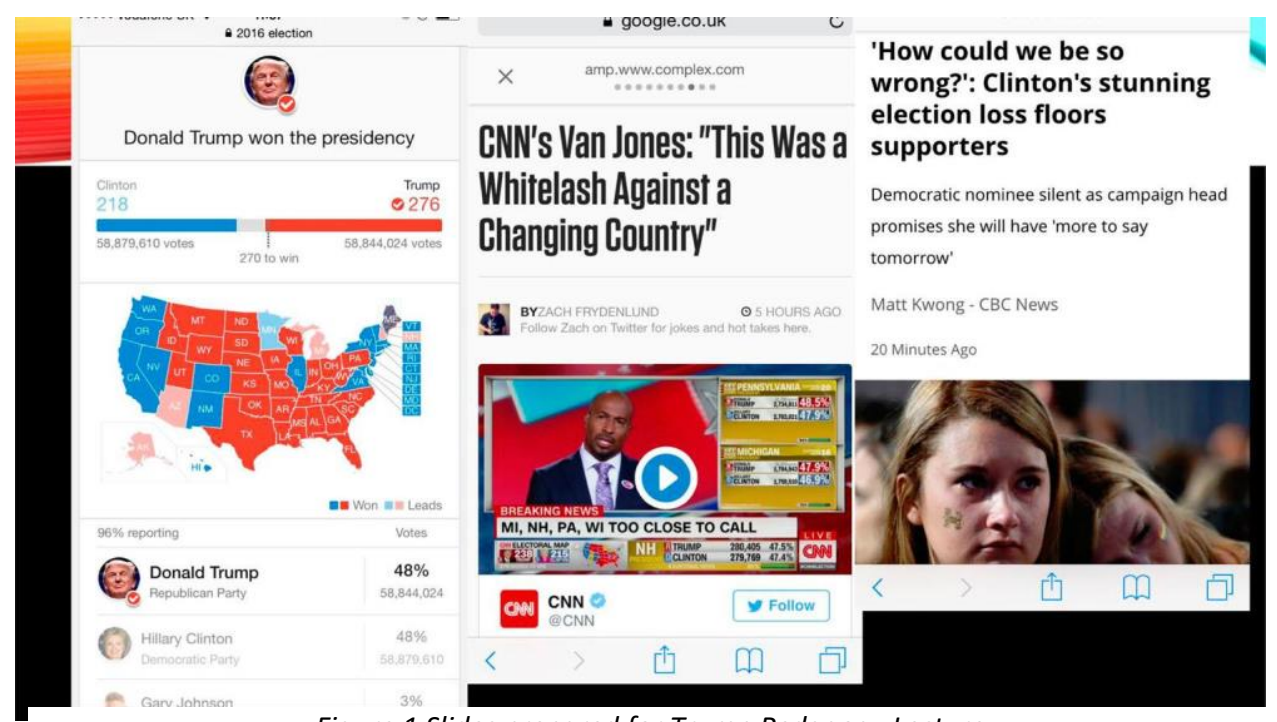

Figure 1 Slides prepared for Trump Pedagogy Lecture.

identities with relative degrees of privilege and oppression defined through access to structural power (Crenshaw 1991). We discussed how white women who are anti-feminist and heavily invested in heteropatriarchal norms and ideology related to women's economic dependence on men (Lawrence and Ringrose 2018).

In counterpoint to Trump's promotion of racist and sexist 'common sense', I argued it is important to clarify Trump's discursive 'identity positions' (Brah and Phoenix 2004) in relation to racism and sexual violence. I specifically drew upon Julia Lalond's definition of Trump as a 'RACIST RAPIST' (Figure 2) to highlight these identity positions and provoke debate. What is also significant, however is that when I was asked to turn the session into a blog for the UCL IOE the blog moderators requested I remove reference to the claim of Trump as racist rapist as too provocative and sensational. This is important in how our feminist pedagogies are monitored as we act as a public representative of our universities. 
Note the common disclaimer on Twitter that academics are tweeting in a personal capacity rather than on behalf of their university - but can the two be so easily disentangled given we generate our theory and research outputs as employees of our higher education institutions? I consider questions of who owns our feminist academic public pedagogy and the surveillance of academic 'truth claims' (Foucault 1980 ) in a digital hyper- connected, era of public networks further as I proceed (Jenkins, Ford, and Green 2012).

We also looked at tweets that demonstrated how commentators were battling over a hierarchy of oppression trying to define the events as defined through sexism OR racism (Figure 3).

One Tweet (see Figure 3) claiming America is 'more sexist than racist' was useful to spark a discussion of intersectionality as a theory of intermeshed complexity. We dis-cussed the inability to tease apart these dimensions in the lived experience of Black women (Crenshaw 1991) and our positionality and social location in relation to privilege and feelings of defensiveness in relation to whiteness (Frankenburg 1993). Going around the room to gather reflections on the election, it was striking that a group of white USA women in the room were crying, mirroring the tweet images we had discussed. We had a useful discussion of whether they felt they must act as the affective containers for white grief and despair, crying on cue as part of ideal white femininity, something that has been discussed at length in feminist social movement literature exploring the need for white women to recognise their privilege (Loza 2014). Black feminism has questioned the defensive practices of crying, asking whether white women are sanctioned or legitimised to cry (Accapadi 2007).

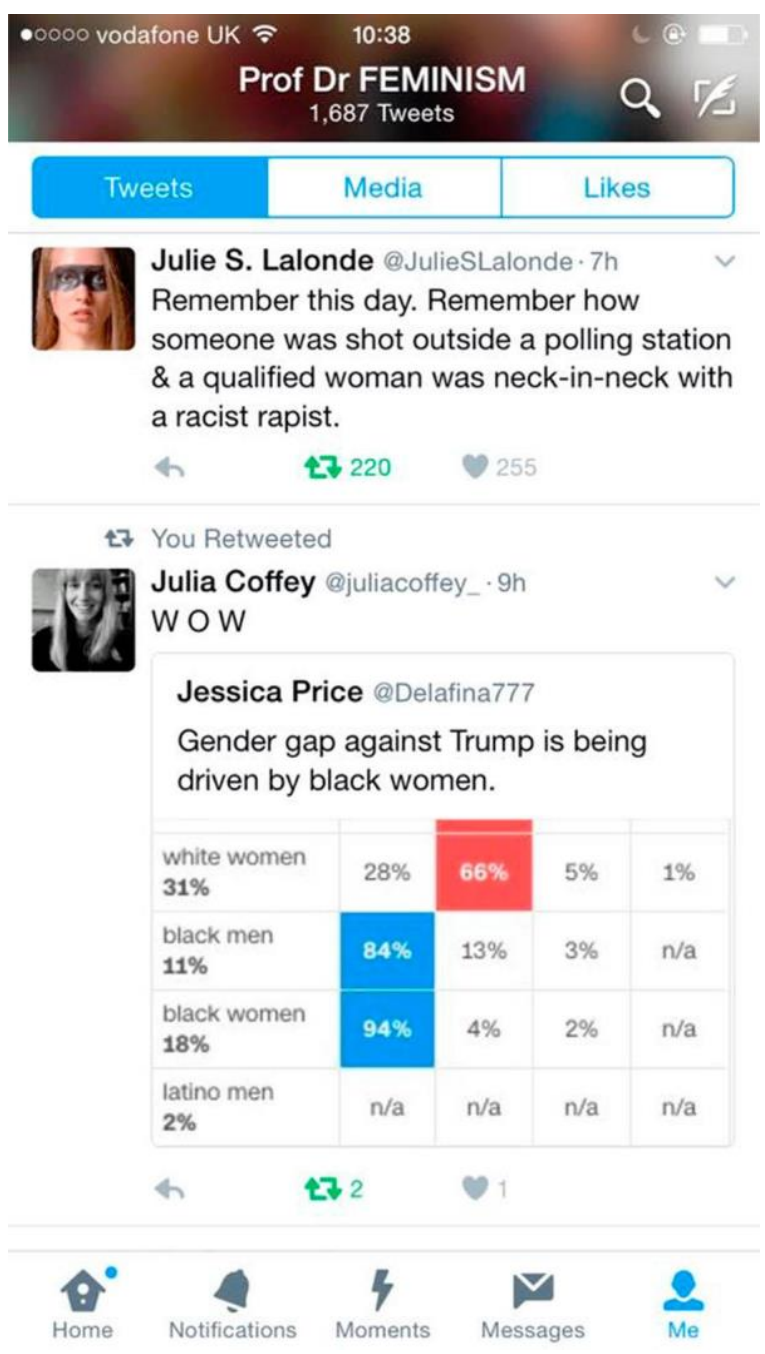

Figure 2. Retweets from my Twitter account. 
I was offered a unique opportunity to draw upon my own doctoral research which explored tensions and difficulty in anti-racist feminism in Women's Studies classrooms, and the difficulty some white women experienced in feeling able to confront their racialized privileges (Ringrose 2007). I used these findings to discuss how privilege is not individualised and we need to understand how we are differentially located in institutional and structural power dynamics. In counterpoint, Victoria Showunmi brought up the figure of the Black woman who is angry yet 'resilient' (Collins 1990). Students then related this to character education in British schools - noting how meritocratic dis-courses are calling upon 'minority' students to bottle up their courage and resilience in order to do well in the face of austerity measures and cutbacks in the UK schooling market.

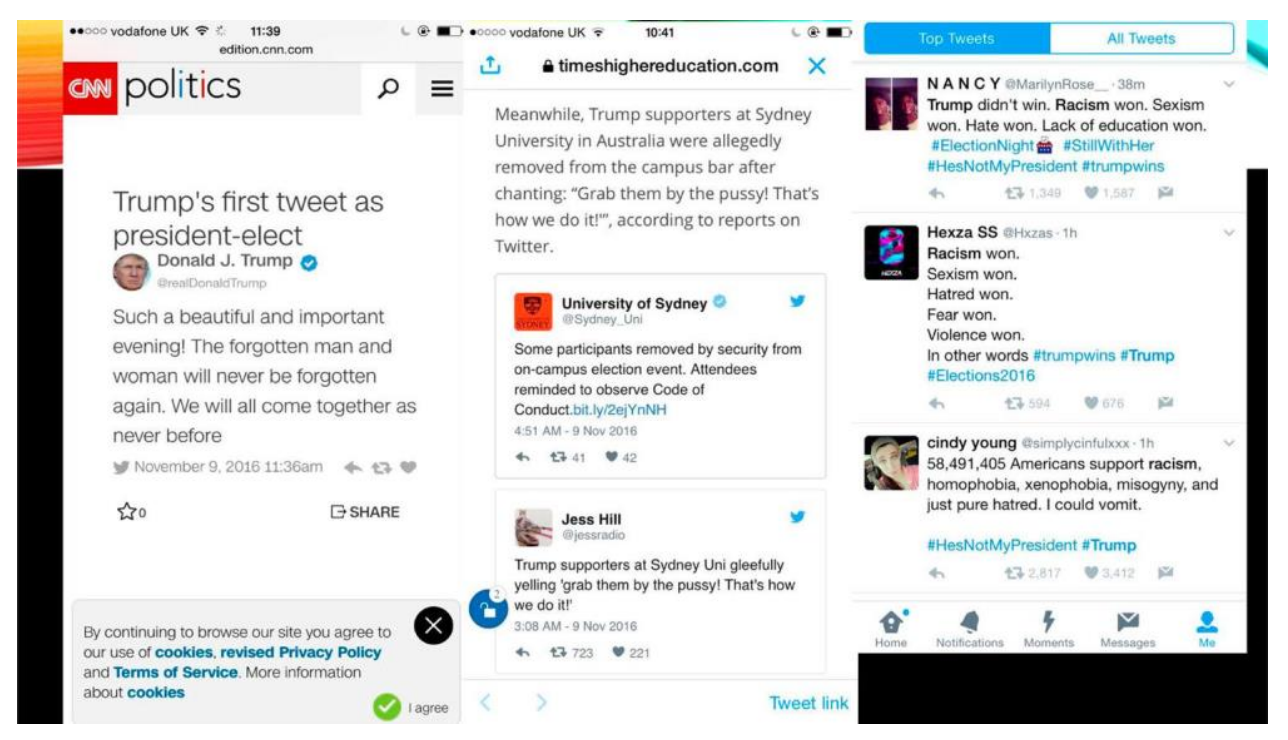

Figure 3. Slides prepared for Trump Pedagogy Lecture.

The only Black woman from the USA in the class declared that Trump ran the election like a reality TV show, arguing despite Hilary Clinton winning the Democrat lead she couldn't win because she was associated with 'establishment', reporting she told her Black friends 'not to vote'. A British white man noted that 'the system is broken' in the vein of the 'broken Britain' trope suggesting everything is corrupt and today was no different than yesterday; and although Trump was terrible it wasn't about an individual man but a failing system. I sensed some recuperative and or 'aggrieved entitled' masculinity politics possibly emerging here (Lingard 2003; Kimmel 2017/18) and so I used this as a moment to point out that the failing system was also masculinised in ways we couldn't dismiss. Similarly, a white British woman continued by saying, you couldn't now turn on the individual voters as they had exercised their 'democratic rights'. But democracy and 'choice' are questionable notions in a context of mass media conditioning, what Brian Massumi calls 'affective attenuation' where media loops of Trump's angry face work on an endless repetitive cycle to normalise this performance of aggressive masculinity. We also discussed the idea of Trump's behavioural contagion (Sampson 2012) pointing to how young men at the University of Sydney chanted 'grab them by the pussy' on campus to celebrate Trump's presidency (see Figure 3). Students noted their concern that rape culture could be sustained and circulate more aggressively in a world where performances of aggressive masculinity and misogyny are increasingly acceptable, or in fact rewarded, and the man who publicly stated he would 'grab them [women] by the pussy[s]' is now the leader of the 'free world'.

One hopeful aspect of the election, was the age demographic under 25 's voting overwhelmingly in favour of Hilary Clinton. School teachers in the room discussed wanting to take this discussion of young people in America's support of Hilary Clinton back to their students and to have discussions about social justice with young people in their own classrooms. We explored how deconstructing Trump Pedagogy means addressing the contradiction between anti-bullying policies in school and the types of performative displays of regressive masculinity on show from Trump which legitimate bullying behaviour (see Horton 2017). We concluded by invoking the feminist slogan the 'the personal is political' and the Black feminist mantra 'the masters tools will never dismantle the masters' house' (Lorde 1984). This 
was accompanied by meme images and quotes from Michelle Obama calling out Trump's condoning of sexual violence and bullying behaviour. We discussed how digital feminist meme and tweet cultures offered easy access to an alternative ethics of feminist respect, consent and consideration (Kanai 2016). Championing these digital tools could make it easier for teachers and lecturers to practice and spread feminist pedagogical practices in our own lives (Guillard 2016) to confront the hypocrisy and para-doxes of the Trump era where a prominent world leader's 'punch em' in the face' mentality is celebrated.

\section{Mediated misogyny and anti-feminism}

Having detailed the experience of applying Black feminist intersectionality theory to understand Twitter and news media around the results of the 2016 Trump election, I now want to briefly turn next to the dynamics of my own participation in Twitter as a public medium for practicing my feminist pedagogy around the election events. During the election night, I sent out key discursive messages I've discussed, such as retweeting that Trump is a racist rapist (see Figure 2), and retweeting the messages racism won and sexism won (see Figure 3). In this way, I used the digital affordances of hashtags and trends on Twitter to spread a message, something l've argued else-where offers a unique pedagogical dimension for feminists to raise awareness and spreading ideas around gender and sexual violence (see Mendes, Ringrose, and Keller 2018). Following these tweets and retweets about Trump I was trolled for several consecutive days after the election, receiving a stream of aggressive, demeaning and some-times sexually abusive tweets. One user, @Warpath, whose profile reads 'NEVER Politically Correct, FOREVER Ethically Correct', suggested in response to claims that Trump was 'racist rapist' 'can't change skin colour, better to chop off those testicles, obviously not getting much out of them anyhow.' Another twitter user suggested I should be cleansed from the academic system. Another, @YoungGun dubbed me a 'self-loathing wimpy snowflake' due to my feminist beliefs, which were akin to "reconditioning attempted by Nazis"'

Twitter, has been widely critiqued for its hostility, with hate speech increasingly normalised and women disproportionately targeted by trolls due to its communicative structures which allow any public user to directly @ one another and to do keyword and hashtag searches (Rightler-McDaniels and Hendrickson 2014). Jane's (2017) extensive research on 'online misogyny' discusses how social media has spawned new forms of digital misogyny or 'trolling' what she calls 'e-bile', whilst Vickery and Everbach (2018) discuss their concept of 'mediated misogyny' which is made easier to spread and proliferate through digital platforms. What is significant is that trolling is disproportionately targeted at women (Cole 2015), and that it is gendered in nature with the content often drawing upon sexually degrading language exerting online forms of sexual harassment (Megarry 2014) or what Powell and Henry (2017) call digitally facilitated sexual violence. This online abuse is not random. Ging (2017) has mapped the presence of what she terms the Manosphere comprised in part of Man's Rights Activist (MRA) group; a connected online subculture of blogs, forums, and alternative media publications 'centred around hatred, anger and resentment of feminism specifically, and women more broadly' (Wilkinson 2016). The tweets I received were also aimed at invalidating claims about sexual violence as hearsay and false (Ging 2017). This is what l'd like to term post-truth anti-feminism (see also Ringrose, forthcoming). What Linda Alcoff calls epistemic fallacy around rape and sexual survivors (Alcoff 2018) is propagated through online networks, which dispute statistics around sexual violence and rape allegations. This is connected to wider 'alt-right' patterns of media manipulation, 'disinformation', such as 'fake news' online (Marwick and Lewis 2017). For example, in response to claims that Trump was a rapist @YoungGun states, 'just because a woman says it doesn't mean it's true'; and 'I demand proof of this racism and "misogyny" 4 your info most men talk like that in lkr rooms'. A Twitter user by the name of, A Man Without Wings suggests, 'just because you say something so often you believe it yourself, doesn't make it true to anyone else'. These MRAs comprise digital networks where followers rapidly join in to 'troll' hashtags and then accounts. Many of the tweets I received were connected through a visible network, once one tweeted others would retweet and quote the tweet to issue new comments. This cumulates quickly and after waking up to an onslaught of abuse several mornings in a row, and given I had received violent sexual threats on my Twitter account in the past, I decided to remove Prof Dr FEMINISM from my Twitter handle, reasoning that possibly my creative use of the handle to use my titles to authorise feminist views was somehow catalysing the 
organised response. I also made this decision to adjust my public identity on Twitter given I have had to manage several bouts of abusive commentary in online news forums. In 2008 following headlines about my work on feminism in schools, commentators said I was 'a crazy woman', questioned tax payers contributing to my salary, urged me to get a 'proper job', called my research 'left wing garbage', labelled me a 'bra burning feminist' and made derogatory personal comments about my appearance and clothes (see Ringrose 2013 for a fuller account). More recently my research was lambasted in a Daily Mail article reporting on government funded research on young people's experiences of gender diversity where the journalist attacked my research as 'beyond parody' and 'loopy feminist drivel' (Thompson 2016). Deflated by the coverage itself, I did not catalogue or analyse the online comments of this article, but it is significant that on the back of that media coverage the following month I received what I call a 'hate post card' to my office at the University College London. It featured a classical image of a reclining woman with an arrow through her heart on the cover and a veiled message threatening that I should find a new vocation. Anti-feminist threats travel beyond the digital sphere into the material context of our working and personal lives as feminist academics (McRobbie 2016). Thus, we see that when we perform public pedagogy as feminist academics through digital social and news media we face a range of challenges.

\section{Conclusion}

In this brief discussion, I have sought to illuminate how we can use digital platforms like Twitter to investigate power, privilege and positionality, taking my experience of intra-acting with Donald Trump's 2016 election via Twitter and using this as a basis for my lecturing as a case in point. We are offered unique teaching and learning opportunities from these new media ecologies but they also presents risks. Feminist pedagogues are confronted with the denial and attack of our intersectional feminist analyses in the 'post-truth' Trump era. As argued by Marwick and Lewis (2017)

Far-right groups are quickly developing techniques of 'attention hacking' to increase the visibility of their ideas through the strategic use of social media, memes, and bots-as well as by targeting journalists, bloggers, and influencers to help spread content [including] white supremacist thought, Islamophobia, and misogyny through irony and knowledge of internet culture.

These dynamics of mediated misogyny, racism and hate also travel back in and through our teaching and learning as feminists in the material spaces of work and home. What we need, therefore, is to be armed with the knowledge and understanding of the types of logics of 'aggrieved entitled masculinity' (Kimmel 2013) that propel both offline and online misogyny so that we can devise adequate strategies to tackle it.

\section{$\underline{\text { Note }}$}

1. For a fuller discussion of this episode and a discussion of reclaiming the term snow-flake (see Regehr and Ringrose 2018).

Disclosure statement

No potential conflict of interest was reported by the author.

\section{$\underline{\text { References }}$}

Accapadi, Mamta Motwani. 2007. "When White Women Cry: How White Women's Tears Oppress Women of Color." College Student Affairs Journal 26 (2): 208-215.

Alcoff, Linda Martin. 2018. Rape and Resistance. London: Polity Press.

Brah, A., and A. Phoenix. 2004. "Ain't I a Woman? Revisiting Intersectionality." Journal of International Women's Studies 5 (3): 75-86.

Butler, J. 1990. Gender Trouble. London: Routledge. 
Carrigan, M. 2016. Social Media for Academics. London: SAGE.

Cole, K. K. 2015. "“It's Like She's Eager to be Verbally Abused”: Twitter, Trolls, and (En) Gendering Disciplinary Rhetoric." Feminist Media Studies 15 (2): 356-358.

Collins, P. H. 1990. Black Feminist Thought: Knowledge, Consciousness and the Politics of Empowerment. New York: Routledge.

Crenshaw, K. 1991. "Mapping the Margins: Intersectionality, Identity Politics, and Violence Against Women of Color." Stanford law Review 43 (6): 1241-1299.

Deleuze, G. 2005. Logic of Sense. New York, NY: Bloomsbury Publishing.

Duffy, E. D., and J. D. Pooley. 2017. "Facebook for Academics": The Convergence of Self-Branding and Social Media Logic on Academia.edu. Social Media and Society. http://journals.sagepub. com/doi/full/10.1177/2056305117696523.

Foucault, Michel. 1980. Power/Knowledge. New York: Pantheon.

Frankenburg, R. 1993. White Women, Race Matters: The Social Construction of Whiteness. Minneapolis, MN: University of Minnesota Press.

Ging, D. 2017. "Alphas, Betas, and Incels: Theorizing the Masculinities of the Manosphere." Men and Masculinities, 1-20. http://journals.sagepub.com/doi/full/10.1177/1097184X17706401.

Guillard, Julianne. 2016. "Is Feminism Trending? Pedagogical Approaches to Countering (SI)activism." Gender and Education 28 (5): 609-626.

Horton, P. 2017. "Trumped: School Bullying, Power, and US Election Rhetoric Paul Horton." Paper presented at the World Antibullying Forum, Stockholm, Sweden, May 7-9.

Jane, E. J. 2017. Misogyny Online: A Short (and Brutish) History. London, Thousand Oaks \& New Delhi: Sage.

Jenkins, Henry, Sam Ford, and Joshua Green. 2012. Spreadable Media. New York: New York University Press.

Kanai, Akane. 2016. "Sociality and Classification: Reading Gender, Race and Class in a Humorous Meme." Social Media and Society 2 (4): 1-12. doi:10.1177/2056305116672884.

Kimmel, Michael S. 2013. Angry White Men: American Masculinity at the End of an Era. New York, NY: Nation.

Kimmel, M. S. 2017/18. "Trump's Angry White Men.” The World Today. https://www. chathamhouse.org/publications/twt/trump-s-angry-white-men.

Lawrence, Emilie, and Jessica Ringrose. 2018. "@NoToFeminism, \#FeministsAreUgly and Misandry Memes: How Social Media Feminist Humour is Calling out Antifeminism." In Emergent Feminisms: Complicating a Postfeminist Media Culture, edited by Keller Jessalynn, and Ryan Maureen, 211-232. New York: Routledge.

Lingard, B. 2003. "Where to in Gender Policy in Education After Recuperative Masculinity Politics?" International Journal of Inclusive Education 7 (1): 33-56.

Lorde, Audre. 1984. Sister Outsider: Essays and Speeches. Trumansburg, NY: Crossing Press.

Loza, Susana. 2014. "Hashtag Feminism,\#SolidaritylsForWhiteWomen, and the Other \#FemFuture." Ada: A Journal of Gender, New Media \& Technology 5. http://adanewmedia.org/ 2014/07/issue5-loza/. 
Lupton, D., I. Mewburn, and P. Thomson. 2018. The Digital Academic, Critical Perspectives on Digital Technologies in Higher Education. London: Routledge.

Marwick, A., and R. Lewis. 2017. Media Manipulation and Disinformation Online. https:// datasociety.net/pubs/oh/DataAndSociety_MediaManipulationAndDisinformationOnline.pdf.

Massumi, Brian. 2015. Politics of Affect. Cambridge: Polity Press.

McRobbie, A. 2016. “Anti-Feminism, Then and Now”, Opendemocracy.net, November 28.

Megarry, J. 2014. "Online Incivility or Sexual Harasssment: Conceptualising Women's Experiences in the Digital Age." Women's Studies International Forum 47: 46-55.

Mendes, K., Ringrose, J, and J. Keller. 2018. Digital Feminist Activism: Girls and Women Fight Back Against Rape Culture. New York: Oxford University Press.

Powell, Anastasia, and Nicola Henry. 2017. Sexual Violence in a Digital Age. Basingstoke: Palgrave Macmillan.

Regehr, K., and J. Ringrose. 2018. "Celebrity Victims and Wimpy Snowflakes." In Mediating Misogyny: Gender, Technology, and Harassment, edited by J. Vickery and T. Everbach, 353- 370. London: Palgrave.

Rich, Emma, and Andy Miah. 2014. "Understanding Digital Health as Public Pedagogy: A Critical Framework." Societies 4: 296-315. doi:10.3390/soc4020296.

Rightler-McDaniels, J. L., and E. M. Hendrickson. 2014. "Hoes and Hashtags: Constructions of Gender and Race in Trending Topics." Social Semiotics 24 (2): 175-190.

Ringrose, J. 2007. "Rethinking White Resistance: Exploring the Discursive Practices and Psychical Negotiations of 'Whiteness' in Feminist, Anti-Racist Education." Race, Ethnicity and Education 10 (3): 321-342.

Ringrose, J. 2013. Post-Feminist Education? Girls and the Sexual Politics of Schooling. London: Routledge.

Ringrose, J. Forthcoming. "Toxic Teen Mediated Masculinity and Antifeminism in Schools." Paper to be presented at Consoling Passions Conference 2018, Bournemouth, UK, July 11-13.

Ringrose, J., and Victoria Showunmi. 2016. Calling out Trump Pedagogy: Turning the 2016 USA election into a teachable moment. GEA - Gender and Education Association, UCL Institute of Education, November 10. http://www.genderandeducation.com/issues/donald-trump-wins-us-election-geamembers-respond-2/.

Sampson, Tony D. 2012. Virality. Minneapolis, MN: University of Minnesota Press.

Strom, K. J., and Adrian D. Martin. 2017. "Thinking with Theory in an Era of Trump." Issues in Teacher Education 26 (3): 3-22.

Thompson, D. 2016. Gender Madness, Daily Mail. http://www.dailymail.co.uk/debate/article3422060/Gender-madness-Trans-girl-Demi-boy-Inter-sex-Government-survey-asking-13-year-old-spick-25-genders-absurd-dangerous.html\#ixzz58J5oefHf.

Trifonas, Peter Pericles. 2012. Learning the Virtual Life: Public Pedagogy in a Digital World. New York: Routledge. ISBN 978-0-415-89204-9.

Vickery, J., and T. Everbach. 2018. Mediating Misogyny: Gender, Technology, and Harassment. London: Palgrave. 
Wilkinson, A. 2016. "We Need to Talk About the Online Radicalization of Young, White Men". The Guardian, November 15. 